\title{
Idiopathic Environmental Intolerance: A comprehensive model
}

DOI:

$10.1177 / 2167702617693327$

\section{Document Version}

Accepted author manuscript

Link to publication record in Manchester Research Explorer

\section{Citation for published version (APA):}

Van den Bergh, O., Brown, R., Petersen, S., \& Witthöft, M. (2017). Idiopathic Environmental Intolerance: A comprehensive model. Clinical Psychological Science, 5(3), 551-567. https://doi.org/10.1177/2167702617693327

\section{Published in:}

Clinical Psychological Science

\section{Citing this paper}

Please note that where the full-text provided on Manchester Research Explorer is the Author Accepted Manuscript or Proof version this may differ from the final Published version. If citing, it is advised that you check and use the publisher's definitive version.

\section{General rights}

Copyright and moral rights for the publications made accessible in the Research Explorer are retained by the authors and/or other copyright owners and it is a condition of accessing publications that users recognise and abide by the legal requirements associated with these rights.

\section{Takedown policy}

If you believe that this document breaches copyright please refer to the University of Manchester's Takedown Procedures [http://man.ac.uk/04Y6Bo] or contact uml.scholarlycommunications@manchester.ac.uk providing relevant details, so we can investigate your claim.

\section{OPEN ACCESS}




\title{
Running head: IDIOPATHIC ENVIRONMENTAL INTOLERANCE
}

Idiopathic Environmental Intolerance: A comprehensive model ${ }^{1}$

\author{
Omer Van den Bergh* \\ Health Psychology, University of Leuven, Leuven, Belgium \\ Richard J. Brown \\ School of Psychological Sciences, University of Manchester, UK \\ Sibylle Petersen \\ Institute for Health and Behaviour, University of Luxembourg, Luxembourg, and \\ Health Psychology, University of Leuven, Belgium \\ Michael Witthöft \\ Clinical Psychology, Psychotherapy, and Experimental Psychopathology, \\ University of Mainz, Mainz, Germany.
}

Author Note

Omer Van den Bergh, Health Psychology, University of Leuven, Belgium.

Michael Witthöft, Clinical Psychology, Psychotherapy, and Experimental Psychopathology, University of Mainz, Germany.

Sibylle Petersen, Institute for Health and Behaviour, University of Luxembourg, Luxembourg and Health Psychology, University of Leuven, Belgium

Richard J. Brown, School of Psychological Sciences, University of Manchester, UK

\footnotetext{
${ }^{1}$ In press, Clinical Psychological Science
} 
Correspondence concerning this article should be addressed to Omer Van den Bergh, Health Psychology, Tiensestraat 102, University of Leuven, Belgium. Contact:

omer.vandenbergh@kuleuven.be 


\begin{abstract}
Idiopathic environmental intolerance refers to a group of poorly understood health conditions characterized by heterogeneous somatic symptoms that occur in response to environmental triggers, but for which no physiological causes can be found. We focus on three varieties, namely symptoms attributed to (1) chemical substances; (2) to electromagnetic fields; and (3) to infrasound and vibroacoustic sources. As no clear link with organ pathology or dysfunction has been established so far, we review critical evidence about alternative causal mechanisms as a platform for a novel unifying model of these conditions. There is consistent evidence that expectancy and nocebo mechanisms are critically involved. Using recent predictive coding models of brain functioning, we describe a comprehensive new model to explain how symptoms come about and become linked to specific environmental cues. This new model integrates phenomenally different pathologies, suggests testable new hypotheses and specifies implications for treatment.
\end{abstract}

Keywords: environmental intolerance, multiple chemical sensitivity, infrasound hypersensitivity, nocebo 
Idiopathic Environmental Intolerance: A comprehensive model

\section{Introduction}

Idiopathic Environmental Intolerance (IEI) refers to a group of health conditions characterized by a wide range of somatic symptoms that purportedly arise in response to environmental triggers, but for which there is no solid evidence of an underlying physiological cause. In the present paper, we focus on three varieties of IEI: (1) Multiple chemical sensitivity (MCS), or chemical intolerance, which refers to symptoms attributed to chemical sources such as diesel exhausts, cleaning products, pesticides, smoke etc.; (2) Electromagnetic hypersensitivity syndrome (EHS), or idiopathic environmental intolerance attributed to electromagnetic fields (IEI-EMF), which refers to symptoms attributed to electromagnetic sources such as power lines, remote controllers, mobile phones and their relay stations; (3) Infrasound hypersensitivity (IHS), which refers to symptoms attributed to low frequency noise, such as that produced by wind turbines.

The IEI syndromes are controversial because of (1) the absence of an established link with organ pathology or dysfunction; (2) the occurrence of heterogeneous symptoms following exposure to a variety of environmental sources that are often unrelated in a physical or chemical sense, and at intensities well below levels known to be harmful; (3) the failure to document perceptual hypersensitivity in well-controlled blinded exposure studies; (4) consistent evidence for the role of psychological and behavioral processes, such as hypervigilance to bodily responses, somatic attributions and enhanced emotional responding to the purported sources of the symptoms; and (5) the large symptom overlap with somatoform disorders (Bailer, Witthöft, Paul, Bayerl \& Rist, 2005) and other functional syndromes, such as chronic fatigue syndrome (CFS), fibromyalgia, war syndromes, etc. (Wessely, Nimnuan \& Sharpe, 1999). 
So contested are the causes of IEI that the diagnosis has provoked clinical and scientific disputes, media controversy, legal struggles and even political debate. Disagreements between patients and medical professionals about the nature of IEI are commonplace, hampering the treatment process. The debate is often caught in a mind-body trap, taking the form of unproductive discussions over whether the condition is "real" or "imaginary", "physical" or "psychological". There is a pressing need for an account of IEI that bridges the gap between these positions. To that end, the present paper develops an integrative account for these conditions within a biopsychosocial framework. We begin by describing clinical features, and then summarize pertinent research on potential mechanisms. We go on to describe a theoretical model that details relevant causal processes and testable predictions, before discussing implications for treatment. Other IEI's such as Sick Building Syndrome and several food and alcohol intolerances share many characteristics with these IEI's, but will not be discussed here in order to limit the scope of this paper when reviewing the clinical features and summarizing critical studies suggesting potential mechanisms. However, the health conditions discussed here should be considered exemplars for IEI's in general, and we believe that our comprehensive new model largely accounts for other IEI's as well.

\section{Clinical Characteristics And Prevalence}

Several excellent reviews exist, summarizing case definitions, clinical characteristics and prevalence of the different varieties of IEI. We provide a brief sketch of the main conditions based on the conclusions of these reviews.

MCS. Overall, the symptom profile of MCS is relatively non-specific, including a general feeling of malaise and symptoms (in order of prevalence) related to the central nervous system and the musculoskeletal, gastrointestinal, dermal, auditory, mucosal and respiratory, and cardiovascular systems (Dantoft, Andersson, Nordin, \& Skovbjerg, 2015; 
Labarge \& McCaffrey, 2000). This order of prevalence is not always found, however, and the profile varies considerably between individuals (Eis, Helm, Mühlinghaus, et al., 2008). Emotional and mood-related symptoms are generally reported, as well as functional impairment and reduced quality of life.

Toxicological causes for MCS appear implausible from both an empirical and theoretical perspective (e.g. Hetherington \& Battershill, 2013; Staudenmayer, Binkley, Leznoff, \& Phillips, 2003). The symptoms of MCS are typically attributed to a range of substances in the environment that are chemically unrelated, occurring at doses well below levels known to be harmful. Symptom triggers are mostly common substances, such as cleaning products (88.4\% of cases), tobacco smoke (82.6\%), perfume (81.2\%), pesticides $(81.2 \%)$, and vehicle fumes $(72.5 \%)$. However, there are no clear associations between categories of pollutants and sets of symptoms (Eis et al., 2008).

Clinical MCS is probably the tip of an iceberg of highly prevalent self-reported chemical hypersensitivity among the general population. Roughly 9 to $33 \%$ of the population reports hypersensitivity to everyday chemicals (Hausteiner, Bornschein, Bickel, Zilker, \& Forstl, 2005; Johansson, Bramerson, Millqvist, Nordin, \& Bende, 2005), whereas 0.5 to $6 \%$ report doctor-diagnosed MCS (Berg, Linneberg, Dirksen, \& Elberling, 2008; Kreutzer, Neutra, \& Lashuay, 1999). In about $75 \%$ of cases, full-blown MCS co-occurs with one or more comorbid mental disorders, most frequently somatoform (DSM-IV: 35-59\%), affective (19\%), anxiety (21\%) and psychotic disorders (13\%; Bornschein, Hausteiner, Zilker, \& Förstl, 2002; Bailer et al., 2005; Hausteiner et al., 2006). Female gender is a consistent risk factor. The condition leads to severe distress, chronic health concerns, substantial lifestyle modifications and social handicap. Sufferers often change household cleaning and personal hygiene products $(76.8 \%)$, buy water and/or air filtration systems $(47.8 \%)$, change residence $(13 \%)$ and avoid places contaminated by tobacco smoke or perfumes. About $13 \%$ report job 
loss due to their hypersensitivity (Caress \& Steinemann, 2003; Kreutzer et al., 1999).

Longitudinal studies suggest that MCS is a very stable condition with a poor prognosis (Bailer, Witthöft, \& Rist, 2008a).

IEI-EMF. IEI-EMF is characterized by a variety of non-specific and idiosyncratic symptoms that largely overlap with the symptoms of MCS. Persons characterizing themselves as having IEI-EMF report on average 2.7 different symptoms, particularly sleep disorders (58\%), headaches (41\%), nervousness or distress (19\%), fatigue (18\%), and concentration difficulties (16\%; Genuis \& Lipp, 2012; Röösli, Moser, Baldinini, Meier, \& BraunFahrländer, 2004). Other symptoms are palpitations, chest distress, dizziness/nausea, skinrelated sensations (e.g. itching, tickling, redness, burning), sensations of warmth of the ear and tinnitus/ringing of the ear. The complaints are typically attributed to exposure to mobile phone base stations (74\%), mobile phones (36\%), cordless phones (29\%) and power lines (27\%). No distinct symptoms related to specific field sources or different frequencies have been identified, although the symptom profile in response to mobile phone devices seems somewhat more restricted than to electrical equipment in general (Baliatsas, van Kamp, Hooiveld, Yzermans, \& Lebret, 2014; Van Dongen, Smid, \& Timmermans, 2011).

The condition is less widespread than MCS and varies across locations. In populationbased studies, the prevalence ranges from 1.5\% (Sweden; Hillert, Berglind, Arnetz, \& Bellander, 2002), 3.2\% (California; Levallois, Neutra, Lee, \& Hristova, 2002) to 8-10\% (Germany; INFAS, 2006). Increased prevalence rates of mental disorders, particularly major depression, generalized anxiety disorder, and somatoform disorders, have been observed among individuals with EHS (Landgrebe, Frick, Hauser, Langguth, Rosner, Hajak, \& Eichhammer, 2008). The burden of the symptoms is substantial enough to motivate the majority of persons to consult public authorities and to take action to reduce the symptoms, 
such as avoiding and/or removing perceived sources of electromagnetic radiation (Röösli et al., 2004).

IHS. A relatively recent form of IEI is infrasound hypersensitivity (IHS), sometimes called "wind turbine syndrome" or "vibroacoustic syndrome". IHS refers to a variety of bodily complaints in different organ systems, such as otological/vestibular symptoms (dizziness, tinnitus, earache, nausea), cognitive symptoms (concentration and memory problems), cardiovascular symptoms (palpitations, hypertension), systemic symptoms (fatigue, sleep problems) and a set of psychological symptoms (frustration, distress, anger, depression, anxiety) that are thought to be caused by the direct physiological effects of these turbines. The symptoms vary according to the distance from industrial wind turbines, and are associated with significantly reduced quality of life and thoughts about wanting to leave the exposure situation to restore well-being (McMurty \& Krogh, 2014). IHS should be distinguished from general distress related to wind farms, which is more strongly related to visual cues and to attitudinal factors than wind turbine noise itself (Knopper \& Ollson, 2011), and from hyperacusis in which everyday, low-level sounds are considered more distressing than normal. However, given elevated comorbidities with other "medically unexplained" symptoms (MUS), it is likely that classification boundaries between IHS and other soundrelated MUS are often blurred (Paulin, Andersson, \& Nordin, 2016). Various pathophysiological mechanisms have been advanced, such as EMF generated by the turbines, shadow flicker from rotor blades, audible noise, low-frequency noise (LFN) and infrasound, but no direct link between these physical factors and the symptoms of IHS has been established, except for that between annoyance and self-reported sleep disturbance at noise levels $>35 \mathrm{~dB}$ (A) (Knopper, Ollson, McCallum, Whitfield Aslund, Berger, Souweine, \& McDaniel, 2014; Crichton \& Petrie, 2015). 
This brief overview suggests that a substantial percentage of the population, women more so than men, report a range of non-specific symptoms in different organ systems and causally attribute them to salient factors in their environment. These environmental factors can be chemical, electromagnetic or vibroacoustic in nature, but no evidence can be found that the symptoms are related to the actual physical properties of the suspected sources.

\section{Biopsychosocial mechanisms}

Numerous studies suggest that the symptoms of IEI vary according to the sufferer's awareness of, and expectancies about, their exposure, as well as several factors related to the saliency and perceived significance of the environmental features in question. This clearly suggests a role for biopsychosocial processes in IEI. In this section we consider some of the potential mechanisms in this regard, as a platform for our own theoretical account.

MCS. A laboratory model to investigate the variables that might influence symptom reporting in response to chemicals was developed by Van den Bergh and co-workers. It starts from the observation that many MCS patients report toxic exposure as a trigger for their illness, but that stress conditions are also mentioned as a context for the development of MCS. The experimental set-up involves repeated administrations of a compound stimulus consisting of a harmless odor and a respiratory stimulus that modifies carbon dioxide levels in the blood $\left(\mathrm{PCO}_{2}\right)$. In one version (mimicking a toxic exposure), hypercapnia is induced by breathing $\mathrm{CO}_{2}$-enriched air (typically 5-10\% $\mathrm{CO}_{2}$ ). In another version, hypocapnia is induced by instructed hyperventilation (mimicking a frequently occurring response to stress). Both diversions from normocapnia cause symptoms in multiple organ systems in association with the harmless odor. This means that the participant first learns to expect symptom episodes when a particular odor is presented. Subsequently, the odor is presented by itself in similar breathing trials while, unbeknownst to the participant, the $\mathrm{CO}_{2}$ level is normalized (room air is presented in the first version, normocapnic hyperventilation in the second version). 
Symptom reports and physiological responses are measured and compared with a control odor that is mixed with normal air and presented an equal number of times.

An extensive series of laboratory experiments (see Table 1 for an overview) has shown that, once a predictive association had been established between symptoms and a harmless but odorous chemical, those symptoms can be induced by presenting the odor alone. This expectancy-induced nocebo effect (the negative counterpart of the placebo effect, in which a negative expectancy manipulation induces [the worsening of] symptoms (Benedetti, Lanotte, Lopiano, \& Colloca, 2007) is modulated by several important variables. It is stronger in persons with high trait negative affectivity (NA; see further), when the odor is foul smelling, and after exposure to threatening MCS-related reading material. Learned symptoms also generalize to new odors following an unpleasantness gradient. They persist for many days but can be "unlearned", although less so if the induced symptoms are more intense initially. Perceived rather than objective contingencies between odor cues and symptom episodes are critical for symptom learning, and even thinking about being in a particular room can become a trigger for learned symptoms.

insert Table 1 about here

Such findings clearly document the heuristic value of this human laboratory model of MCS, and may explain how trigger-symptom associations might develop in the first place. They are also consistent with the observation that MCS patients are no more able than healthy persons to detect chemical exposures in double-blind laboratory exposures, with symptoms only being triggered when the individual is aware of the exposure (Das-Munshi, Rubin, \& Wessely, 2007). 
In addition, several cognitive factors and mechanisms may further contribute to maintaining symptom experiences in the same way as in patients with somatoform disorders. For example, heightened attentional allocation towards symptom words, better recognition memory and more negative automatic evaluative responses to MCS-related trigger words (e.g. pesticides, solvents, air pollution) was found in MCS patients compared to healthy controls (Witthöft, Gerlach, \& Bailer, 2006; Witthöft, Rist, \& Bailer 2009). These cognitive features suggest chronically active somatic memories in the brains of MCS patients, which are thought to play a role in perpetuating the broader category of medically unexplained somatic symptoms (Brown, 2004).

Patients with MCS also attribute bodily symptoms less frequently to psychological causes compared to other patients with multiple somatic symptoms (Bailer et al., 2005) and are more biased towards accepting somatic or external causes. Longitudinal studies have found that a somatic symptom attribution style as well as trait negative affect predict somatic symptoms in patients with MCS (Bailer, Witthöft, Bayerl, \& Rist, 2007; Bailer, Witthöft, \& Rist 2008b). Interestingly, trait negative affect is also an important moderator in the experimental studies demonstrating symptom learning in healthy participants (see Table 1).

Pre-existing modern health worries (e.g. pollution; Petrie \& Wessely, 2002) are also positively associated with symptoms of MCS in both clinical and non-clinical samples (Bailer Witthöft, \& Rist, 2008a). The predicted increase in complaints in a longitudinal study comparing symptoms before and after environmental pesticide spraying in New Zealand (Petrie Broadbent, Kley, Moss-Morris, Horne, \& Rief, 2005) suggests that such worries foster and amplify the perception of bodily sensations and somatic symptoms.

Absorption represents another construct that is specifically related to increases in symptoms in MCS compared to healthy participants and patients with other chronic somatic symptoms. Absorption refers to the tendency to become engrossed in the object of attention and 
lose awareness of other stimuli, which can result in strong emotional responses when acoustic, visual, or olfactory cues are encountered (Tellegen and Atkinson, 1974). The trait is associated with elevated hypochondrical concerns (McClure \& Lilienfeld, 2002) and in a longitudinal study, absorption at baseline positively predicted chemical odor sensitivity and specific MCS symptoms 32 months later in a sample of MCS patients (Witthöft, Rist, \& Bailer, 2008).

IEI-EMF. As in the case of MCS, the exact etiology of IEI-EMF is unknown. Doubleblind randomized controlled exposure studies could not find evidence for a bioelectromagnetic mechanism in terms of a physical association between actual exposure levels to EMFs and subjective symptom reports (e.g. Rubin, Hahn, Everitt, Cleare \& Wessely, 2006), nor could characteristic physiological effects attributable to EMF exposure be observed in patients with IEI-EMF (Rubin, Hillert, Nieto-Hernandez, \& Oftedal, 2011). Laboratory studies have also shown that patients cannot reliably discriminate between real and sham EMF exposures (Röösli, 2008).

On the other hand, symptoms only seem to emerge with aware exposure to EMF (Rubin, Cleare, \& Wessely, 2008), and the more restricted symptom profile in response to mobile phone compared to electrical equipment in general is most likely due to differences in attribution and somatization processes (Johansson, Nordin, Heiden, \& Sandström, 2010; Rubin et al., 2008). Participants with IEI-EMF also overestimate the occurrence of real EMF exposures and high levels of symptoms in patients with IEI-EMF are equally observed under conditions of real and sham exposure to EMFs (Rubin et al., 2010). This suggests a critical role for nocebo mechanisms in symptom development and maintenance (e.g. Szemerszky, Köteles, Lihi, \& Bárdos, 2010). Interestingly, an fMRI study found that sham radiation by mobile phones administered to patients with IEI-EMF resulted in symptom experiences that correlated with alterations in neural activity in the same brain circuits that were involved in processing experimentally induced heat pain (i.e. ACC, insula, Landgrebe et al., 2008). 
Laboratory studies in healthy participants also indicate a critical role for nocebo mechanisms in the initial development of symptoms in IEI-EMF. Szemerszky et al. (2010), for example, found that self-reported symptoms following sham EMF exposure were reliably predicted by individual differences in somatization. In another study, participants from the general population were randomly assigned to watch either a media report on the health risks of EMF or to a control film condition without reference to health risks, before being confronted with a sham exposure session. The most anxious participants reported more somatic symptoms and were more likely to attribute them to the non-existent EMF after watching the health-threatening film (Witthöft \& Rubin, 2013). Elevated symptom reports following the EMF sham exposure were also predicted by pre-existing worries about the possible harmful effects of EMF. These results show that person characteristics (e.g. state anxiety, modern health worries) and contextual factors (e.g. media reports) interact in the development of symptoms that characterise IEI-EMF.

IHS. The condition of IHS probably represents the most recent environmental syndrome and its etiology and pathogenesis remain largely unexplained. In line with MCS and IEI-EMF, the most plausible causal mechanism is that the symptoms of IHS result from negative beliefs and expectations (nocebo effect), moderated by psychological factors related to distress and personality (Crichton, Dodd, Schmid, Gamble, Cundy, \& Petrie, 2014; Crichton, Dodd, Schmid, Gamble, \& Petrie, 2014; Crichton, Chapman, Cundy, \& Petrie, 2014; Crichton \& Petrie, 2015; Rubin et al., 2014). For example, in a sham-controlled double blind exposure study in which healthy participants were randomly assigned either to a negative expectation condition (highlighting possible negative health effects of infrasound) and a positive control condition (where no adverse health effects were highlighted), participants in the negative expectation condition reported significantly stronger symptoms in response to both actual infrasound exposure and sham exposure. In another provocation study 
with healthy participants, symptom reports were significantly reduced after providing information on the nature of the nocebo effect (Crichton \& Petrie, 2015). These findings suggest that the nature of expectation rather than the actual infrasound exposure itself determines the degree of somatic symptom reports (Crichton, Dodd, Schmid, Gamble, Cundy et al., 2014). Further support for the critical role of beliefs and expectations comes from historical and geographical distributions of health complaints in response to wind turbines, which suggest that they are linked to patterns of media coverage and subsequent risk perception (Chapman, George, Waller, \& Cakic, 2013).

\section{A common mechanism?}

As there is little consistent evidence for exaggerated sensitivity to environmental triggers in IEI patients, enhanced responsivity seems a better term, capturing the evidence that these patients often rate environmental triggers as disproportionately intense or unpleasant and that they report a variety of symptoms to them. The idea of exaggerated responsivity in response

to actual or sham exposures is at the heart of the pathology of the three IEI's we discussed so far, suggesting that there might be a common mechanism. In that respect, the idea of central sensitization has become particularly attractive as a potential transdiagnostic explanatory concept (Dantoft, et al., 2015, for a review on MCS).

Evidence suggesting a common mechanism may also be found in studies on brain activations in patients with IEI compared with controls. Table S2 in the Supplemental Material available online reviews this evidence. Despite a wide variety of brain imaging techniques, these studies generally show differences between patient groups and healthy controls in the activity of brain areas that are related to stimulus salience and/or to interoception (thalamus, anterior cingulate cortex, anterior insula). In that respect, the study of Landgrebe et al (2008) on IEI-EMF patients is particularly interesting. First, it shows that symptoms emerge as a result of sham exposures to mobile phone radiation, meaning that there 
simply was no stimulus at all (which is hard to reconcile with the notion of central sensitization). Second, it elicited enhanced activity in basically the same brain areas as real nociceptive stimulation. This evidence is consistent with an interpretation that IEI reflects enhanced responding towards environmental triggers, based on the meaning the stimuli have acquired and on the expectations that are raised by contextual cues. This observation is also in line with the odor conditioning studies (see above, Table 1) showing that symptoms may become triggered by harmless stimuli as a result of acquired meaning and valence of these stimuli that subsequently induce nocebo expectancies. This suggest that also central sensitization effects might be mediated by the acquired meaning and valence of stimuli and their dynamic change over repeated stimulations.

\section{Summary}

The three environmental conditions reviewed above are characterised by a diverse and overlapping set of physical symptoms, which occur in the absence of compelling empirical evidence for an underlying disease process or physiological trigger-symptom association. In this sense, they are comparable to other MUS, such as those seen in the general population (Watson \& Pennebaker, 1989) and in somatoform disorders. In all three cases, there is clear evidence that negative expectations trigger/amplify the symptom experiences in question, implicating a nocebo effect as the underlying phenomenon. This process is evidently moderated by contextual information (e.g. provided by media reports, activist reports, social modelling), which can increase or decrease symptom reports and specific symptom attributions. It seems to be more likely in individuals with a tendency to attribute symptoms to external causes and to deny possible psychological explanations.

This work provides a useful basis for understanding IEI but key questions remain. In particular, while there is good evidence that the symptoms of IEI result from expectations and beliefs, how does this process actually operate? How is it even possible for a symptom to 
exist in the absence of a (peripheral) pathophysiological cause? Most of the work on causal mechanisms has also been conducted on one specific IEI, with little or no attempt to articulate the similarities and differences between the variants of IEI in terms of underlying processes. As a result, our understanding of IEI remains largely descriptive, resulting in a lack of theoretically driven treatment strategies. In the next section we attempt to address these shortcomings by providing a unifying framework that articulates (a) the precise mechanisms underlying the development of symptoms in IEI; (b) how these symptoms become linked to particular environmental sources; and (c) how they are maintained over time, leading to chronic and complex conditions such as MCS, EHS, and IHS.

\section{A New Model}

As somatic symptom experiences and chronic somatic symptom distress have a central role in IEI, our account is based on a general symptom perception framework (Van den Bergh, Witthöft, Petersen, \& Brown, in press) that is informed by cognitive-psychological models of symptom perception (e.g., Brown 2004; Cioffi 1991) and rests on the concepts of predictive coding and Bayesian inference (see e.g., Friston 2005; Hohwy 2012; Clark, 2013, Barrett \& Simmons, 2015). We begin by describing that framework before outlining how symptom-trigger associations might emerge in this system, leading to the phenotype of a specific IEI variant. We then consider future empirical tests of this model and key clinical implications.

\section{Symptom Perception-as-inference}

A fundamental challenge of the brain is to detect statistical regularities, or patterns, in its own neural activity to create an adaptive model of the world, including its own internal state. Rather than passively receiving input, the brain makes sense of the world by generating inferences based on prior experiences, which then act as constraints for new input in a probabilistic way (i.e., new inputs are interpreted in light of what they are likely to be, given 
previous experience). These neural representations or models result from a continuous interplay across multiple hierarchical levels - from low level sensory input to high level abstractions - between predictions generated by previously learned models ("priors") and actual sensory input. The discrepancy between predicted and actual sensory inputs at each hierarchical level results in prediction errors that are propagated throughout the system in a process of error minimization. This eventually leads to a posterior model that best accounts for the prediction errors and reflects the combined influence of the prior and the actual input. Conscious experience corresponds to the posterior model that the system settles upon as the most likely explanation of what is happening in the world (Howhy, 2012).

The system realizes error minimization in three ways: (1) by adapting the prior model to accommodate the actual input (broadly speaking, "changing expectations"); (2) by actively operating upon the world to generate input that fits the predictions of the prior model (broadly speaking, looking for evidence that meets our expectations; so-called active inference); and (3) by changing how the brain samples (or attends to) sensory input (Barrett \& Simmons, 2015). In this continuous interplay of bottom-up information (prediction errors) and top-down influences (predictions), it is important to note that both are interdependent, meaning that predictions impact on predictions errors and vice versa (see below), and that they interact at multiple hierarchical levels rather than at one step in the information processing sequence (Büchel, Geuter, Sprenger, \& Eippert, 2014).

Priors, prediction errors and posterior models should be thought of as probability distributions that represent statistical regularities in neural activity with a mean and a variance (or its inverse, i.e. precision). The relative impact of the prior model (i.e. what the system predicts is present) versus the model representing the input (i.e. what is actually present) on the posterior model (i.e. what the system concludes is present) will be determined by the precision of the distributions: a prior model with high precision in the context of imprecise 
inputs is likely to have a strong impact on the posterior model, whereas the reverse is true when high precision inputs are combined with a prior model that is imprecise. This reflects the idea that models with high precision are more likely to be trustworthy.

As the brain cannot know whether any residual prediction error represents random information or is amenable to further minimization, it has to learn the conditions under which particular models are likely to be adaptive. This is accomplished by developing contextdependent expectations about the precision of its inputs, which determine how much weight is given to the prediction errors in the perceptual process ("precision optimization"; Hohwy, 2012). The implication is that contextual cues may have an important impact on the eventual posterior model that corresponds to conscious experience.

The present perspective emphasizes a constant interaction of counter-flowing streams of information at multiple hierarchical levels and therefore surpasses accounts that locate specific functions in specific brain areas. Barrett and Simmons (2015) recently developed a model describing how predictive coding of interoceptive information is implemented in the brain (Embodied Predictive Interoceptive Coding (EPIC) model). Central to this model are cortical columns of granular, agranular and (intermediate) dysgranular cortices across hierarchically organized lamina subserving networks of corticocortical connectivity, consisting of anatomically different cells acting as prediction, prediction error and precision neurons. Importantly, Barrett and Simmons (2015) suggest that agranular visceromotor regions, comprising mid-cingulate, anterior cingulate, posterior ventromedial prefrontal cortices and parts of the anterior insula, are relatively insensitive to prediction error signals due to precision-weighting factors and aspects of the cytoarchitecture, typically resulting in rather small interoceptive prediction errors. The implication is that interoceptive perception (the posterior model) is largely dominated by prior expectations: "interoceptive perception is largely a construction of beliefs that are kept in check by the actual state of the body (rather 
than vice versa)" (Barrett \& Simmons, 2015, p. 424). Recent evidence further suggests that low precision of interoceptive prediction errors may also result from various sources, such as cytokines and (chronic) HPA-axis activation, influencing the structural and/or functional characteristics of interoceptive areas in the brain (Harshaw, 2015; Schulz \& Vögele, 2015). These considerations suggest that symptom perception in general, but even more so when interoceptive sensitivity is compromised by earlier inflammatory and stress-related activations, is highly sensitive to the influence of prior expectations and contextual cues.

Applying this general conceptualization of how the brain works to interoception and symptom perception allows for an understanding of when and how the relationship between physiological (dys)function and the conscious experience of bodily symptoms varies (see also Edwards, Adams, Brown, Pareés, \& Friston, 2012; Büchel et al., 2014; Van den Bergh et al., in press; Brown \& Reuber, 2016, for similar accounts). The relative precisions of the prior model and the actual physiological input determine the degree to which the symptoms experienced reflect sensory input from within the body versus prior expectations. In the extreme case, symptom reports may be completely dissociated from sensory input (as in MUS, placebo and nocebo phenomena) when specific cues or the context affords excessive precision to priors representing symptoms.

Insert Figure 1 about here

\section{Sources of Symptoms in IEI}

Building on this framework, we suggest that the symptoms of IEI result from two main processes (Figure 1): (i) benign physiological disturbances that produce imprecise 
sensory signals, which are then amplified and shaped by high precision priors within the system; and (ii) pairing of the resulting symptoms with environmental stimuli that eventually enables those stimuli to elicit symptoms in the absence of physiological disturbance or distinctive interoceptive input, via a process of interoceptive conditioning.

Several physiological disturbances related to activations of the hypothalamic pituitary adrenal (HPA) and/or sympathetic adrenal medullary (SAM) stress axis, and their effects on the autonomic, immune and endocrine systems, are likely to be key. Each of these systems is sensitive to behavioral conditioning, implying that their activation is sensitive to anticipation (Ulrich-Lai \& Herman, 2009). This could account for cases of MCS that start with a toxic exposure, but in which resulting symptoms remain and generalize after physiological recovery from the accident (Miller, 1994). The typically frightening nature and implications of toxic exposure confers vulnerability to chronic activation of the stress response system after somatic recovery, via post-traumatic reactions and/or worry about long-term health risks. There is evidence, for example, that perseverative thinking about potential causes and consequences of stressors prolongs stress axis activation (Ottaviani, Thayer, Verkuil, Lonigro, Medea, Couyoumdjian, et al., 2015), potentially creating a vicious circle when symptoms themselves become the subject of perseverative cognitions.

Another source of physiological disturbance in IEI may result from stress-related hyperventilation (HV). $\mathrm{HV}$ is a context-dependent stress response, which is very sensitive to expectations, emotions and emotional imagery (Van Diest, Winters, Devriese, Vercamst, Han, Van de Woestijne, et al., 2001). It affects multiple organ systems and is associated with a range of imprecise symptoms (i.e., those that are weaker, more systemic and widespread, and with poor on/off boundaries; Van den Bergh et al., in press), but is difficult to objectify in laboratory tests because $\mathrm{pCO}_{2}$-levels may or may not be low at the actual time of measurement. Sensations arising from HV are therefore particularly susceptible to distortion 
by pre-existing beliefs, as the brain tries to create a meaningful model from vague neural patterns. Consistent with this, it is known that (1) IEI is more prevalent among stress-sensitive persons; (2) there is substantial overlap between IEI and HV symptoms, such as intermittent flares of fatigue and weakness, lightheadedness, concentration and memory problems, shortness of breath, palpitations and "racing heart", gastro-intestinal problems and feelings of anxiety or depression; (3) exposure of MCS patients to their chemical trigger induces HV in 73\% (Leznoff, 1997); (4) a substantial number of IEI-MCS patients meet diagnostic criteria for panic disorder, with HV being a likely common ground between the two (Poonai, Antony, Binkley, Stenn, Swinson, Corey, et al., 2000).

\section{Creating A Posterior Model For Symptoms}

In parallel with low precision somatic stimulation, a multitude of factors in the internal or external environment may promote different prior models, each generating predictions about potential causes for the stimulation. Since causality cannot be observed directly, it has to be inferred. Various cues inform this inference, including the spatial and temporal relationship between events, their novelty and intensity, and their consistency with one's own actions, beliefs and worries (Sloman \& Lagnado, 2015; Holyoak \& Cheng, 2011). In the case of a toxic exposure, the toxic event is both highly salient and the effects emerge in close spatiotemporal proximity to it. This promotes a highly precise model about symptoms being

caused by toxic agents. Once this model is established as a prior in the system, it will generate predictions against which subsequent somatic sensations are compared. If those sensations are imprecise, as will be the case for sensations arising from $\mathrm{HV}$ and chronic stress, the prior model will dominate perception, resulting in an experience that is consistent with pre-existing expectations. Two major consequences may follow. First, the prior model may eventually come to determine the posterior model completely, leading to the experience of symptoms that are dissociated from peripheral bodily inputs (see above, and Table 1 for examples). 
Other examples of complete dominance of the prior model over perception are symptom reports triggered by sham exposure to either EMF (Witthöft \& Rubin 2013) or infrasound (Crichton, Dodd, Schmid, Gamble et al., 2014). Secondly, when low precision somatic prediction errors induce active inference to minimize them (i.e. overt actions in the world to generate inputs that fit existing predictions), the model will promote a selective search to find toxic elements, such as sources of EMF or infrasound in the environment that confirm expectations. Such searches will be characterised by confirmatory bias and retrospective sense-making ("I have symptoms, so something toxic/harmful is present here"; see also the feedback route in Figure 1). Once potentially toxic/harmful elements have been included in the posterior model (e.g. "it must be the diesel exhaust"), they will in turn promote strong priors with the potential to produce symptom experiences in the absence of distinct physiological sensations, eventually leading to a self-perpetuating cycle that generalizes to ever more potentially toxic/harmful agents.

Strong priors may be experience-based, such as in the toxic exposure and conditioning example, but also verbal information and contextual cues may promote strong and precise priors determining the posterior model, as is demonstrated by the extensive literature on the placebo/nocebo effect (e.g. Büchel et al., 2014; Enck, Bingel, Schedlowski, \& Rief, 2013). This may explain why media and activist-provided information enhancing the threat value of environmental stimuli may contribute to "modern health worries" and thereby elevated symptom reports (Winters, Devriese, Van Diest, Nemery, Veulemans, Eelen, et al., 2003; Rubin \& Witthöft, 2013; Crichton, Dodd, Schmid, Gamble, Cundy et al. 2014; Crichton, Dodd, Schmid, Gamble et al., 2014). In addition, salient (novel) environmental cues, such as ubiquitous cell phones, remote controllers and/or windmills, may serve as a ground for strong priors when combined with threatening information about potential harm, eventually determining the posterior model underlying the experience of symptoms. A self-fulfilling 
prophecy is likely to ensue, as the posterior model generates strong prior predictions on subsequent occasions.

An important implication of this view is that the strength of the relationship between objective indicators of physiological dysfunction and self-reported symptoms is a matter of degree that can vary across contexts and can change over time. For example, self-reported symptoms may start as a result of physiological damage from toxic exposure and/or of stressrelated hyperventilation and may gradually evolve into symptoms unrelated to objective indicators of physiological dysfunction. When presumed environmental triggers elicit defensive behaviors and stress-related activation, these may contribute to further coloring the clinical picture. The present view also integrates and overarches the role of expectations, conditioning and central sensitization.

\section{Individual Differences and Vulnerabilities}

Several stable trait variables may moderate the relative influence of priors and prediction errors on the conscious perception of symptoms, and thereby the risk of developing and maintaining IEI. We will briefly discuss three key factors in this regard: negative affectivity (NA), absorption and gender.

Persons scoring high on NA have a pervasive tendency to experience negative mood states, have a negative self-perception and are more sensitive to threat in themselves and the world around them. These behavioral characteristics result from an over-reactive evaluative system and poor inhibitory capacity (Costa \& McCrae, 1987; Hariri, 2009). NA is a risk factor for developing MUS in general (Van den Bergh, Bogaerts, \& Van Diest., 2015), and high NA persons with MUS show a poor correspondence between experimentally induced somatic episodes and self-reported symptoms (Van den Bergh, Winters, Devriese, Van Diest, Vos, \& De Peuter et al., 2004; Bogaerts, Notebaert, Van Diest, Devriese, De Peuter, \& Van den Bergh, 2005; Bogaerts, Janssens, De Peuter, Van Diest, \& Van den Bergh, 2010). Several 
brain imaging studies in groups with MUS show greater activation of affective networks when processing somatic information, coupled with a failure to counter-regulate unpleasantness (Kwan, Diamant, Pope, Mikula, Mikulis, \& Davis, 2005; Van Oudenhove \& Aziz, 2013). NA also moderates symptom learning in response to odors in laboratory studies (Van den Bergh, Stegen, \& Van de Woestijne, 1997; Van den Bergh, Winters, Devriese, \& Van Diest, 2002) and was a predictor of the development and persistence of chemical intolerance in a longitudinal study in the general population (Skovbjerg, Christensen, Ebstrup, Linneberg, Zachariae et al., 2015). Why are these people more vulnerable to developing IEI? We suggest three main reasons. First, they are more prone to adopt strong prior beliefs about environmental threats (Yiend, 2010). Second, greater activation of affective (stress-related) networks will result in more low precision prediction errors (Paulus \& Stein, 2006). Third, evidence suggests that they have an altered sampling strategy for error minimization (Barrett $\&$ Simmons, 2015). For example, their retrospective evaluation of a somatic episode is less determined by discriminative sensory information and more by a global evaluative response (Bogaerts, Wan, Van Diest, Stans, Decramer, \& Van den Bergh, 2012; Walentynowicz, Bogaerts, Van Diest, Raes, \& Van den Bergh, 2015). Moreover, they differentiate less and are more biased by a priori knowledge when asked to classify interoceptive sensations of different intensities (Petersen, von Leupoldt, \& Van den Bergh, 2015a; Petersen, van Staeyen, Vögele, von Leupoldt, \& Van den Bergh, 2015). The absence of detailed sensory-perceptual sampling for prediction errors may explain why elevated symptom reporting occurs in these persons simply by looking at negative affective pictures and then filling out a symptom questionnaire (Bogaerts et al., 2010; Constantinou, Bogaerts, Van Diest, \& Van den Bergh, 2013; Constantinou, Van Den Houte, Bogaerts, Van Diest, \& Van den Bergh, 2014), and why patients with somatic symptom disorder display reduced specificity of health-related autobiographical memories (Walentynowicz, Raes, Van Diest, \& Van den Bergh, 2016). In 
sum, high NA persons with elevated MUS seem to sample the sensory-perceptual elements of a somatic experience less extensively and tend to focus on the affective elements, making them more vulnerable to arrive at a posterior model of their somatic state that is less informed by (or loosely coupled with) actual sensory-perceptual information.

A second vulnerability factor for IEI is absorption (see above). The tendency to become absorbed is associated with enhanced activity in attention and executive control networks (Grant, Duerden, Courtemanche, Cherkasova, Duncan, \& Rainville, 2013) and with difficulties in keeping the overall context in mind during demanding tasks (Kliegel, Mahy, Voigt, Henry, Rendell, \& Aberle, 2013). This suggests that people high in absorption put an increased gain on low level somatic prediction errors and local priors underlying symptom experiences, but do not keep high-level priors related to "being in this specific reality" active in parallel (Van den Bergh et al., in press). When environmental cues and expectations promote a focus on the individual's somatic state, the increased gain on the priors and somatic prediction errors reduces the influence of contextual constraints, predisposing such individuals to compelling but out-of-context symptom experiences. This is consistent with evidence showing that trait absorption predicts the development of symptoms following exposure to affective pictures and a symptom questionnaire that prompts somatic selfevaluation (Bogaerts, Rayen, Lavrysen, Van Diest, Janssens, Schruers, \& Van den Bergh, 2015).

A third vulnerability factor is gender. MUS and somatoform complaints are consistently more prevalent in women than in men (Barsky, 2001). This female preponderance emerges in the general population (Ihlebæk \& Eriksen, 2003; Hiller, Rief \& Braehler, 2006), in primary care (Aamland, Malterud, \& Werner, 2014; Steinbrecher, Koerber, Frieser, \& Hiller, 2011), as well as in secondary care (Cloninger, Martin, Guze, \& Clayton, 1986; Wessely et al., 1999). MCS (Dantoft et al., 2015) and IEI-EMF (Hillert et al., 
2002) are also more prevalent in women. A wide variety of factors might account for this gender difference in symptom reporting, including biological differences in nociception especially olfaction (Dalton, Doolittle, \& Breslin, 2002; Andersson, Lundberg, Åström, \& Nordin, 2011), in exposure to early adversity (Edwards, Holden, Felitti, \& Anda, 2003), in neuroendocrine stress responses (Bartley \& Fillingim, 2016; Doom, Cicchetti, Rogosch, \& Dackis, 2013), gender-related differences in symptom appraisal, socialization processes and gender roles, as well as gender biases in research and clinical practices (Barsky, 2001; Lorber, Mazzoni, \& Kirsch, 2007). However, two findings are also important to mention. First, in laboratory environments, women are consistently found to be less accurate than men at detecting physiological changes in a variety of bodily systems (Roberts \& Pennebaker, 1994), which seems to correspond with gender-related structural and functional differences in the interoceptive network in the brain (Harshaw, 2015). Second, the gender-related difference in interoceptive accuracy disappears in natural environments. Pennebaker (Roberts \& Pennebaker, 1994; Pennebaker, 1995) suggests that this is due to women being more sensitive to contextual cues when determining their internal state, a difference that may correspond with greater cue utilization in spatial navigation and in social perception in women (EcuyerDab \& Robert, 2004; Hall, 1978). The implication is that contextually driven priors are likely to have a greater influence on women's interoception and symptom perception, which may render women more vulnerable to environmental illnesses.

\section{Summary}

The model presented here builds on the notion that the symptoms of IEI result from a nocebo process driven by expectations and beliefs about the effects of particular environmental stimuli. We have unpacked the mechanisms involved in this process, suggesting that highly precise priors about potential harm from environmental sources, in combination with imprecise or even absent prediction errors (somatic input), shape the 
conscious experience of symptoms. A learning process may also occur, such that somatic experiences come to be triggered by environmental stimuli as a result of frequent pairing between the two. The experiential, verbal and contextual information that creates an expectation of symptoms may also interact with trait-like characteristics of individuals, particularly NA and absorption, making them more vulnerable to developing/perceiving symptoms.

\section{Clinical Implications}

A central tenet of this model is that there is no subjective difference between symptoms that closely reflect somatic input compared to those that reflect a strong prior, although in the latter case there may be little connection with peripheral physiological dysfunction. In this way, it avoids the clinical impasse encountered when no cause can be found for the patient's symptoms and they perceive this as being told that they are "imagining" or "malingering" them. Much as visual illusions are subjectively true but objectively false, so the symptoms of IEI are "real" whether there is a medical explanation or not: each reflects inherent aspects of the neural processes of perception.

The model suggests three main ways of altering the posterior model underlying symptoms, and thereby treating IEI: (1) by altering priors so that they account for prediction errors in a less toxic way; (2) by providing opportunities for active inference to fit these new priors; and (3) by influencing the sampling strategy for somatic input. In what follows, we briefly describe a general treatment strategy based on these theoretical principles.

\section{Providing Alternative Priors for Low Precise Prediction Errors}

Although psychoeducation is rarely sufficient to change posterior models, explaining how different branches of the stress-response system can produce variable multi-organ symptoms is a first step towards developing alternative priors. It may also be helpful to explain that attributing symptoms to a cause can produce a self-fulfilling prophecy in which 
anticipatory stress triggers sensations that seemingly confirm their predictions. Essentially, the patient is given an explanation that enables them to understand how they can have symptoms that seem to be caused by environmental factors when they are not. A further element to explain, preferably by using metaphors or data from experiments, is that the brain makes anticipatory models of these sensations and, if paired with external cues often enough, will reproduce them whenever those cues are encountered, regardless of their actual physical state. Demonstrating that imagining biting in a lemon can produce real salivation, or that imagining being out of breath can induce breathlessness and breathing changes (Van Diest et al., 2001), are instructive. It is also useful to explain how rumination and worrying about one's illness state and prognosis may result in chronic activation of stress response systems and the mental models underlying symptoms, creating a vicious cycle. Deliberately suppressing thoughts/expectations of symptoms can also result in activation of the underlying models, just as trying not to think about a white bear often brings that image to mind. All this information should be given not to convince the patient that s/he is wrong, but as an invitation to explore new ways of thinking about their symptoms and to test whether these alternatives might be correct.

\section{Promoting Active Inference Strategies To Disconfirm Old Priors And To Fit New Ones}

As causal perception is most highly informed by one's own actions, promoting active inference strategies through behavioral testing is particularly effective at changing priors. If hyperventilation seems relevant, voluntary provocation of symptoms in the absence of environmental triggers may disconfirm the prior that symptoms are elicited by them. Exposure to triggers (e.g. cleaning products in the case of MCS) while performing breathing techniques counteracting hypocapnia can also provide useful disconfirmatory evidence to challenge the causal posterior model. Importantly, exposure to triggers should be done with an attitude of "letting go" and avoiding covert mental strategies to control the danger, such as 
checking and scanning of the body, to maximise expectancy-violation experiences (Craske, Treanor, Conway, Zbozinek, \& Vervliet, 2014). This should be consolidated with homework assignments involving repeated exposures to triggers, allowing evidence against the posterior model to accumulate. Other control behaviors, such as frequent medical consultations and avoidance behaviors that are based on the "old" posterior model should also be discouraged, and behaviors that are more consistent with the new model (i.e. handling triggers the same way as other people) should be encouraged.

\section{Changing The Sampling Strategy For Interoceptive Input}

As the symptoms of high trait NA persons are apparently less informed by careful perception of sensory-perceptual details and more influenced by affective elements of the somatic experience, interoceptive exposure to sensory-perceptual inputs from the body may serve two goals. First, repeated exposure to somatic experiences should reduce fear for those sensations. Second, it should improve sensory-perceptual differentiation of somatic inputs (Van den Bergh et al., in press). This should result in more accurate perception of bodily sensations without being overwhelmed/biased by their affective aspects. Consistent with this, Schaefer, Egloff, Gerlach, \& Witthöft (2014) found that improving heartbeat detection in patients with somatoform disorders was associated with a reduction in symptoms when controlling for differences in health anxiety. Other interventions, such as Mindfulness training and/or Acceptance and Commitment Therapy, which include a non-judgemental perception of bodily activity may also produce similar effects on interoceptive differentiation. Ultimately, more accurate interoception combined with new priors will foster the development of posterior models that are closer to actual somatic inputs, resulting in symptomatic improvement.

\section{Conclusions}


This model provides a novel explanatory framework that accounts for heterogeneous and medically unexplained somatic symptoms attributed to diverse environmental agents such as low-dose chemicals, EMF, and infrasound. The model rests on the principles of recent Bayesian predictive coding models of brain functioning, which conceptualize symptom perception as an active inferential process that is highly dependent on prior experiences, expectations, and contextual cues. This model provides a compelling explanation for the obvious paradox inherent in IEI, namely that environmental triggers seem to cause symptoms despite the absence of a pathophysiological link between the two. Future experimental studies that mimic the onset and offset of IEI symptom experiences along central model parameters, as well as clinical studies that test the efficacy of the treatment strategies suggested by the model, are now needed to evaluate its validity and utility. 
All authors contributed in a significant way during all phases of writing this manuscript. All authors have read and approved the final manuscript.

We thank Anne-Kathrin Bräscher for her support in identifying the relevant brain imaging findings.

Omer Van den Bergh was funded by grant OT-10-027 from the Research Council of the University of Leuven. Sibylle Petersen was funded by grant AFR PDR 2013-2 of the Fonds National de la Recherche Luxembourg.

None of the authors has a conflict of interest. 


\section{References}

Aamland, A., Malterud, K., Werner, E. L. (2014). Patients with persistent medically unexplained physical symptoms: A descriptive study from Norwegian general practice. BMC Family Practice, 15(1), 1.

Andersson, L., Lundberg, C., Åström, J., \& Nordin, S. (2011). Chemosensory attention, habituation and detection in women and men. International Journal of Psychophysiology, 79, 316-322. doi:10.1016/j.ijpsycho.2010.11.008

Bailer, J., Witthöft, M., Bayerl, C., \& Rist, F. (2007). Syndrome stability and psychological predictors of symptom severity in idiopathic environmental intolerance and somatoform disorders. Psychological Medicine, 37, 271-281. doi:10.1017/S0033291706009354

Bailer, J., Witthöft, M., Paul, C., Bayerl, C., \& Rist, F. (2005). Evidence for overlap between idiopathic environmental intolerance and somatoform disorders. Psychosomatic Medicine, 67, 921-929. doi:10.1097/01.psy.0000174170.66109.b7

Bailer, J., Witthöft, M., \& Rist, F. (2008a). Modern health worries and idiopathic environmental intolerance. Journal of Psychosomatic Research, 65, 425-433. doi:10.1016/j.jpsychores.2008.05.006

Bailer, J., Witthöft, M., \& Rist, F. (2008b). Psychological predictors of short- and medium term outcome in individuals with idiopathic environmental intolerance (IEI) and individuals with somatoform disorders. Journal of Toxicological Environmental Health. Part A, 71, 766-775. doi:10.1080/15287390801985562

Baliatsas, C., van Kamp, I., Hooiveld, M., Yzermans, J., \& Lebret E. (2014). Comparing non-specific physical symptoms in environmentally sensitive patients: Prevalence, duration, functional status and illness behavior. Journal of Psychosomatic Research, 76, 405-413. doi:10.1016/j.jpsychores.2014.02.008 
Barrett, L. F., \& Simmons, W. K. (2015). Interoceptive predictions in the brain. Nature reviews. Neuroscience, 16, 419-429. doi:10.1038/nrn3950

Barsky, A. J. (2001). Palpitations, arrhythmias, and awareness of cardiac activity. Annals of Internal Medicine, 134, 832-837. doi:10.7326/0003-4819-134-9_Part_2-20010501100006

Bartley, E. J., \& Fillingim, R. B. (2016). Sex differences in pain and stress. In M. Flaten \& M. al'Absi (Eds), Neuroscience of Pain, Stress, and Emotion, 1st Edition, (p 77-91). London, England: Elsevier.

Benedetti, F., Lanotte, M., Lopiano, L., \& Colloca, L. (2007). When words are painful: unraveling the mechanisms of the nocebo effect. Neuroscience, 147, 260-271. DOI:

\subsection{6/j.neuroscience.2007.02.020}

Berg, N. D, Linneberg, A., Dirksen, A., \& Elberling, J. (2008). Prevalence of self-reported symptoms and consequences related to inhalation of airborne chemicals in a Danish general population. International Archives of Occupational and Environmental Health, 81, 881-887. doi:10.1007/s00420-007-0282-0

Bogaerts, K., Janssens, T., De Peuter, S., Van Diest, I., \& Van den Bergh, O. (2010). Negative affective pictures can elicit physical symptoms in high habitual symptom reporters. Psychological Health, 25, 685-698. doi:10.1080/08870440902814639

Bogaerts, K., Millen, A., Li, W., De Peuter, S., Van Diest, I., Vlemincx, E., ... et al., (2008). High symptom reporters are less interoceptively accurate in a symptom-related context. Journal of Psychosomatic Research, 65, 417-424. doi: 10.1016/j.jpsychores.2008.03.019

Bogaerts, K., Notebaert, K., Van Diest, I., Devriese, S., De Peuter, S., \& Van den Bergh, O. (2005). Accuracy of respiratory symptom perception in different affective contexts. 
Journal of Psychosomatic Research, 58, 537-543.

doi:10.1016/j.jpsychores.2004.12.005

Bogaerts, K., Rayen, L., Lavrysen, A., Van Diest, I., Janssens, T., Schruers, K., \& Van den Bergh, O. (2015). Unraveling the relationship between trait negative affectivity and habitual symptom reporting. PloS One, 10:e0115748; doi:10.1371/journal.pone.0115748

Bogaerts, K., Wan, L., Van Diest, I., Stans, L., Decramer, M., \& Van den Bergh, O. (2012). Peak-end memory bias in laboratory-induced dyspnea: A comparison of patients with medically unexplained symptoms and healthy controls. Psychosomatic Medicine, 74, 974-981. doi:10.1097/PSY.0b013e318273099c

Bornschein, S., Hausteiner, C., Zilker, T., \& Förstl, H. (2002). Psychiatric and somatic disorders and multiple chemical sensitivity (MCS) in 264 'environmental patients'. Psychological Medicine, 32, 1387-1394.

Bresseleers, J., Van Diest, I., De Peuter, S., Verhamme, P., \& Van den Bergh, O. (2010). Feeling lightheaded: The role of cerebral blood flow. Psychosomatic Medicine, 72, 672-680. doi: 10.1097/PSY.0b013e3181e68e94.

Brown, R. J. (2004). Psychological mechanisms of medically unexplained symptoms: An integrative conceptual model. Psychological Bulletin, 130, 793-812. doi:10.1037/0033-2909.130.5.793

Brown, R. J., \& Reuber, M. (2016). Towards an integrative theory of psychogenic nonepileptic seizures (PNES). Clinical Psychological Review, 47, 155-170. doi: 10.1016/j.cpr.2016.06.003.

Büchel, C., Geuter, S., Sprenger, C., \& Eippert, F. (2014). Placebo analgesia: A predictive coding perspective. Neuron, 81, 1223-1239. doi:10.1016/j.neuron.2014.02.042 
Caress, S. M., \& Steinemann, A. C. (2003). A review of a two-phase population study of multiple chemical sensitivities. Environmental Health Perspectives, 111, 1490-1497. doi:10.1289/ehp.5940

Chapman, S., St George, A., Waller, K., \& Cakic, V. (2013). The pattern of complaints about Australian wind farms does not match the establishment and distribution of turbines: Support for the psychogenic, 'communicated disease' hypothesis. PloS One 8:e76584; doi:10.1371/journal.pone.0076584

Cioffi, D. (1991). Beyond attentional strategies: Cognitive-perceptual model of somatic interpretation. Psychological Bulletin, 109, 25-41.

Clark, A. (2013). Whatever next? Predictive brains, situated agents, and the future of cognitive science. Behavioral and Brain Sciences, 36, 181-204. doi:10.1017/S0140525X12000477

Cloninger, C. R., Martin, R. L., Guze, S. B., \& Clayton, P. J. (1986). A prospective followup and family study of somatization in men and women. American Journal of Psychiatry, 143(7), 873-878.

Constantinou, E., Bogaerts, K., Van Diest, I., \& Van den Bergh, O. (2013). Inducing symptoms in high symptom reporters via emotional pictures: The interactive effects of valence and arousal. Journal of Psychosomatic Research, 74, 191-196. doi:10.1016/j.jpsychores.2012.12.015

Constantinou, E., Van Den Houte, M., Bogaerts, K., Van Diest, I., \& Van den Bergh, O. (2014). Can words heal? Using affect labeling to reduce the effects of unpleasant cues on symptom reporting. Frontiers in Psychology, 5, 807. doi:10.3389/fpsyg.2014.00807

Costa, P. T., \& McCrae, R. R. (1987). Neuroticism, somatic complaints, and disease: Is the bark worse than the bite? Journal of Personality, 55, 299-316. 
Craske, M. G., Treanor, M., Conway, C. C., Zbozinek, T., \& Vervliet, B. (2014).

Maximizing exposure therapy: An inhibitory learning approach. Behaviour, Research and Therapy, 58, 10-23. doi:10.1016/j.brat.2014.04.006

Crichton, F., Chapman, S., Cundy, T., \& Petrie, K. J. (2014). The link between health complaints and wind turbines: support for the nocebo expectations hypothesis. Frontiers in public health, 2, 220. doi: 10.3389/fpubh.2014.00220

Crichton, F., Dodd, G., Schmid, G., Gamble, G., Cundy, T., \& Petrie, K. J. (2014). The power of positive and negative expectations to influence reported symptoms and mood during exposure to wind farm sound. Health Psychology, 33, 1588-1592. doi:10.1037/hea0000037

Crichton, F., Dodd, G., Schmid, G., Gamble, G., \& Petrie, K. J. (2014). Can expectations produce symptoms from infrasound associated with wind turbines? Health Psychology, 33, 360-364. doi:10.1037/a0031760

Crichton, F., \& Petrie, K. J. (2015). Health complaints and wind turbines: The efficacy of explaining the nocebo response to reduce symptom reporting. Environmental Research, 140, 449-455. doi:10.1016/j.envres.2015.04.016

Dalton, P., Doolittle, N., \& Breslin, P. A. S. (2002). Gender-specific induction of enhanced sensitivity to odors. Nature Neuroscience, 5, 199-200. doi:10.1038/nn803

Dantoft, T. M., Andersson, L., Nordin, S., \& Skovbjerg, S. (2015). Chemical intolerance. Current Rheumatology Reviews, 11, 167-184.

Das-Munshi, J., Rubin, G. J., \& Wessely, S. (2007). Multiple chemical sensitivities: Review. Current Opinion in Otolaryngology and Head and Neck Surgery, 15, 274-280. doi:10.1097/MOO.0b013e328259c360 
Devriese, S., Winters, W., Stegen, K., Van Diest, I., Veulemans, H., Nemery, B., ... et al., (2000). Generalization of acquired somatic symptoms in response to odors: A Pavlovian perspective on Multiple Chemical Sensitivity. Psychosomatic Medicine, 62, 751-759.

Devriese, S., Winters, W., Van Diest, I., De Peuter, S., Vos, G., Van de Woestijne, K., ... et al., (2004). Perceived relation between odors and a negative event determines learning of symptoms in response to chemicals. International Archives of Occupational and Environmental Health, 77, 200-204.

Devriese, S., Winters, W., Van Diest, I., \& Van den Bergh, O. (2004). Contingency awareness in a symptom learning paradigm: Necessary but not sufficient. Consciousness and Cognition, 13, 439-452.

Doom, J. R., Cicchetti, D., Rogosch, F. A., \& Dackis, M. N. (2013). Child maltreatment and gender interactions as predictors of differential neuroendocrine profiles. Psychoneuroendocrinology, 38(8), 1442-1454.

Ecuyer-Dab, I., \& Robert, M. (2004). Have sex differences in spatial ability evolved from male competition for mating and female concern for survival? Cognition, 91(3), 221257.

Edwards, M. J., Adams, R. A., Brown, H., Pareés, I., \& Friston, K. J. (2012). A Bayesian account of 'hysteria'. Brain, 135, 3495-3512. doi:10.1093/brain/aws 129

Edwards, V. J., Holden, G. W., Felitti, V. J., \& Anda, R. F. (2003). Relationship between multiple forms of childhood maltreatment and adult mental health in community respondents: Results from the adverse childhood experiences study. American Journal of Psychiatry, 160(8), 1453-1460.

Eis, D., Helm, D., Mühlinghaus, T., Birkner, N., Dietel, A., Eikmann, T., ... et al., (2008). The German multicentre study on Multiple Chemical Sensitivity (MCS). International 
Journal of Hygiene and Environmental Health, 211, 658-681.

doi:10.1016/j.ijheh.2008.03.002

Enck, P., Bingel, U., Schedlowski, M., \& Rief, W. (2013). The placebo response in medicine: Minimize, maximize or personalize? Nature Reviews Drug Discovery, 12, 191-204. doi:10.1038/nrd3923

Friston, K. (2005). A theory of cortical responses. Philosophical Transactions of the Royal Society of London B Biological Science, 360, 815-836. doi:10.1098/rstb.2005.1622

Genuis, S. J., Lipp, C. T. (2012). Electromagnetic hypersensitivity: Fact or fiction? Science of the Total Environment, 414, 103-112. doi:10.1016/j.scitotenv.2011.11.008

Grant, J. A., Duerden, E. G., Courtemanche, J., Cherkasova, M., Duncan, G. H., \& Rainville, P. (2013). Cortical thickness, mental absorption and meditative practice: Possible implications for disorders of attention. Biological Psychology, 92, 275-281. doi:10.1016/j.biopsycho.2012.09.007

Hall, J. A. (1978). Gender effects in decoding nonverbal cues. Psychology Bulletin, 85(4), 845 .

Hariri, A. R. (2009). The neurobiology of individual differences in complex behavioral traits. Annual Review of Neuroscience, 32, 225-247. doi:10.1146/annurev.neuro.051508.135335

Harshaw, C. (2015). Interoceptive dysfunction: Toward an integrated framework for understanding somatic and affective disturbance in depression. Psychology Bulletin, 141(2), 311 .

Hausteiner, C., Bornschein, S., Bickel, H., Zilker, T., Forstl, H. (2003). Psychiatric morbidity and low self-attentiveness in patients with environmental illness. Journal of Nervous and Mental Disease, 191, 50-55.

doi:10.1097/01.NMD.0000044446.92563.E0 
Hausteiner, C., Bornschein, S., Hansen, J., Zilker, T., \& Forstl, H. (2005). Self-reported chemical sensitivity in Germany: a population-based survey. International Journal of Hygiene and Environmental Health, 208, 271-278. doi:10.1016/j.ijheh.2005.03.006

Hausteiner, C., Mergeay, A., Bornschein, S., Zilker, T., \& Förstl, H. (2006). New aspects of psychiatric morbidity in idiopathic environmental intolerances. Journal of Occupational and Environmental Medicine, 48, 76-82.

Hetherington, L., \& Battershill, J. (2013). Review of evidence for a toxicological mechanism of idiopathic environmental intolerance. Human and Experimental Toxicology, 32, 3-17. doi:10.1177/0960327112457189

Hiller, W., Rief, W., \& Brähler, E. (2006). Somatization in the population: From mild bodily misperceptions to disabling symptoms. Social Psychiatry and Psychiatric Epidemiology, 41, 704-712. doi: 10.1007/s00127-006-0082-y

Hillert, L., Berglind, N., Arnetz, B. B., \& Bellander, T. (2002). Prevalence of self-reported hypersensitivity to electric or magnetic fields in a population-based questionnaire survey. Scandinavian Journal of Work and Environmental Health, 28, 33-41.

Hohwy, J. (2012). Attention and conscious perception in the hypothesis testing brain. Frontiers in Psychology, 3, 96. doi:10.3389/fpsyg.2012.00096

Holyoak, K. J., \& Cheng, P. W. (2011). Causal learning and inference as a rational process: The new synthesis. Annual Review of Psychology, 62, 135-163. doi:10.1146/annurev.psych.121208.131634

Ihlebæk, C., \& Eriksen, H. R. (2003). Occupational and social variation in subjective health complaints. Occupational Medicine, 53(4), 270-278.

INFAS (Institute for Applied Social Sciences). (2006). Identifying the general public's fears and anxieties with regard to the possible risks of high frequency electromagnetic fields of mobile telecommunications (survey 2003, 2004, 2005, 2006). Complete report [in 
German]. Available at: TODO: clickthrough URL http://www.emfforschungsprogramm.de/forschung/risikokommunikation/risikokommunikation_abges /risiko_021.html

Johansson, A., Bramerson, A., Millqvist, E., Nordin, S., \& Bende, M., (2005). Prevalence and risk factors for self-reported odour intolerance: the Skovde population-based study. International Archives of Occupational and Environmental Health, 78, 559564. doi:10.1007/s00420-005-0616-8

Johansson, A., Nordin, S., Heiden, M., \& Sandström, M. (2010). Symptoms, personality traits, and stress in people with mobile phone-related symptoms and electromagnetic hypersensitivity. Journal of Psychosomatic Research, 68, 37-45.

doi:10.1016/j.jpsychores.2009.06.009

Kliegel, M., Mahy, C. E., Voigt, B., Henry, J. D., Rendell, P. G., \& Aberle, I. (2013). The development of prospective memory in young schoolchildren: The impact of ongoing task absorption, cue salience, and cue centrality. Journal of Experimental Child Psychology, 116, 792-810. doi: 10.1016/j.jecp.2013.07.012

Knopper, L. D., Ollson, C. A. (2011). Health effects and wind turbines: A review of the literature. Environmental Health, 10, 78. doi:10.1186/1476-069X-10-78

Knopper, L. D., Ollson, C. A., McCallum, L. C., Whitfield Aslund, M. L., Berger, R. G., Souweine, K., \& McDaniel, M. (2014). Wind turbines and human health. Frontiers in Public Health, 2, 63. doi:10.3389/fpubh.2014.00063

Kreutzer, R., Neutra, R. R., \& Lashuay, N. (1999). Prevalence of people reporting sensitivities to chemicals in a population-based survey. American Journal of Epidemiology, 150, 1-12. 
Kwan, C. L., Diamant, N. E., Pope, G., Mikula, K., Mikulis, D. J., \& Davis, K. D. (2005). Abnormal forebrain activity in functional bowel disorder patients with chronic pain. Neurology, 65, 1268-1277. doi:10.1212/01.wnl.0000180971.95473.cc

Labarge, X. S., \& McCaffrey, R. J. (2000). Multiple chemical sensitivity: A review of the theoretical and research literature. Neuropsychology Review, 10, 183-211.

Landgrebe, M., Frick, U., Hauser, S., Langguth, B., Rosner, R., Hajak, G., \& Eichhammer, P. (2008). Cognitive and neurobiological alterations in electromagnetic hypersensitive patients: Results of a case-control study. Psychological Medicine, 38, 1781-1791. doi:10.1017/S0033291708003097

Levallois, P., Neutra, R., Lee, G., \& Hristova, L. (2002). Study of self-reported hypersensitivity to electromagnetic fields in California. Environmental Health Perspectives, 110, 619-623.

Leznoff, A. (1997). Provocative challenges in patients with multiple chemical sensitivity. Journal of Allergy and Clinical Immunology, 99, 438-442.

Lorber, W., Mazzoni, G., \& Kirsch, I. (2007). Illness by suggestion: Expectancy, modeling, and gender in the production of psychosomatic symptoms. Annals of Behavioral Medicine, 33, 112-6.

McClure, E. B., \& Lilienfeld, S. O. (2002). The dark side of absorption: Empirical associations between an experiential response style and hypochondriacal concerns. Journal of Research in Personality, 36, 573-579

McMurtry, R. Y., \& Krogh, C. M. E. (2014). Diagnostic criteria for adverse health effects in the environs of wind turbines. Journal of the Royal Society of Medicine Open, 5. doi:10.1177/2054270414554048

Meulders, A., Fannes, S., Van Diest, I., De Peuter, S., Vansteenwegen, D., \&Van den Bergh, O. (2010). Resistance to extinction in an odor- $\mathrm{CO}_{2}$ inhalation paradigm with $20 \%$ 
$\mathrm{CO}_{2}$ : Further evidence for a learning account of Multiple Chemical Sensitivity. Journal of Psychosomatic Research, 68, 47-56. doi: 10.1016/j.jpsychores.2009.03.009

Miller, C. S. (1994). White paper: Chemical sensitivity: History and phenomenology. Toxicology and Industrial Health, 10, 253-276.

Ottaviani, C., Thayer, J. F., Verkuil, B., Lonigro, A., Medea, B., Couyoumdjian, A., ... et al., (2015). Physiological concomitants of perseverative cognition: A systematic review and meta-analysis. Psychological Bulletin. doi.org/10.1037/bul0000036

Paulin, J., Andersson, L., \& Nordin, S. (2016). Characteristics of hyperacusis in the general population. Noise and Health, 18(83), 178-184. doi: 10.4103/1463-1741.189244

Paulus, M. P., \& Stein, M. B. (2006). An insular view of anxiety. Biological Psychiatry, 60, 383-387. doi:10.1016/j.biopsych.2006.03.042

Pennebaker, J. W. (1995). Beyond laboratory-based cardiac perception: Ecological interoception. In D. Vaitl, \& R. Schandry (Eds.), From the heart to the brain. The psychophysiology of circulation - Brain interaction (pp. 389-406). Frankfurt: Peter Lang.

Petersen, S., von Leupoldt, A., \& Van den Bergh, O. (2015). Interoception and the uneasiness of the mind: Affect as perceptual style. Frontiers in Psychology, 6, 1408. doi:10.3389/fpsyg.2015.01408

Petersen, S., van Staeyen, K., Vögele, C., von Leupoldt, A., \& Van den Bergh, O. (2015). Interoception and symptom reporting: Disentangling accuracy and bias. Frontiers in Psychology, 6, 732. doi:10.3389/fpsyg.2015.00732

Petrie, K. J., Broadbent, E. A., Kley, N., Moss-Morris, R., Horne, R., \& Rief, W. (2005). Worries about modernity predict symptom complaints after environmental pesticide spraying. Psychosomatic Medicine, 67, 778-782. doi:10.1097/01.psy.0000181277.48575.a4 
Petrie, K. J., \& Wessely, S. (2002). Modern worries, new technology, and medicine. BMJ, $324,690-691$.

Poonai, N., Antony, M. M., Binkley, K. E., Stenn, P., Swinson, R. P., Corey, P., ... et al., 2000. Carbon dioxide inhalation challenges in idiopathic environmental intolerance. Journal of Allergy and Clinical Immunology, 105, 358-363. doi: 10.1016/S00916749(00)90088-5

Roberts, T. A., \& Pennebaker, J. W. (1994). Gender differences in perceiving internal state: Toward a his-and-hers model of perceptual cue use. Advances in Experimental Social Psychology, 27, 143-143.

Röösli, M. (2008). Radiofrequency electromagnetic field exposure and non-specific symptoms of ill health: A systematic review. Environmental Research, 107, 277-287. doi:10.1016/j.envres.2008.02.003

Röösli, M., Moser, M., Baldinini, Y., Meier, M., \& Braun-Fahrländer, C. (2004). Symptoms of ill health ascribed to electromagnetic field exposure-a questionnaire survey. International Journal of Hygiene and Environmental Health, 207, 141-150. doi:10.1078/1438-4639-00269

Rubin, G. J., Burns, M., \& Wessely, S. (2014). Possible psychological mechanisms for "wind turbine syndrome". On the windmills of your mind. Noise Health, 16, 116-122. doi:10.4103/1463-1741.132099

Rubin, G. J., Cleare, A. J., \& Wessely, S. (2008). Psychological factors associated with selfreported sensitivity to mobile phones. Journal of Psychosomatic Research, 64, 1-9. doi:10.1016/j.jpsychores.2007.05.006

Rubin, G. J., Hahn, G., Everitt, B. S., Cleare, A. J., \& Wessely, S. (2006). Are some people sensitive to mobile phone signals? Within participants double blind randomised provocation study. BMJ, 332, 886-891. doi:10.1136/bmj.38765.519850.55 
Rubin, G. J., Hillert, L., Nieto-Hernandez, R., van Rongen, E., \& Oftedal, G. (2011). Do people with idiopathic environmental intolerance attributed to electromagnetic fields display physiological effects when exposed to electromagnetic fields? A systematic review of provocation studies. Bioelectromagnetics, 32, 593-609.

doi:10.1002/bem.20690

Rubin, G. J., Nieto-Hernandez, R., \& Wessely, S. (2010). Idiopathic environmental intolerance attributed to electromagnetic fields (formerly 'electromagnetic hypersensitivity'): An updated systematic review of provocation studies. Bioelectromagnetics, 31, 1-11. doi:10.1002/bem.20536

Schaefer, M., Egloff, B., Gerlach, A. L., \& Witthöft, M. (2014). Improving heartbeat perception in patients with medically unexplained symptoms reduces symptom distress. Biological Psychology, 101, 69-76. doi: 10.1016/j.biopsycho.2014.05.012

Schulz, A., \& Vögele, C. (2015). Interoception and stress. Frontiers in Psychology, 6, 993. doi: 10.3389/fpsyg.2015.00993

Skovbjerg, S., Christensen, K. B., Ebstrup, J. F., Linneberg, A., Zachariae, R., \& Elberling, J. (2015). Negative affect is associated with development and persistence of chemical intolerance: a prospective population-based study. Journal of Psychosomatic Research, 78, 509-514. doi:10.1016/j.jpsychores.2015.02.005

Sloman, S. A., \& Lagnado, D. (2015). Causality in thought. Annual Review of Psychology, 66, 223-247. doi:10.1146/annurev-psych-010814-015135

Staudenmayer, H., Binkley, K. E., Leznoff, A., \& Phillips, S. (2003). Idiopathic environmental intolerance: Part 1: A causation analysis applying Bradford Hill's criteria to the toxicogenic theory. Toxicological Reviews, 22, 235-246. 
Stegen, K., De Bruyne, K., Rasschaert, W., Van de Woestijne, K. P., \& Van den Bergh, O. (1999). Fear-relevant images as conditioned stimuli for somatic complaints, respiratory behavior and reduced end-tidal $\mathrm{pCO}_{2}$. Journal of Abnormal Psychology, 108, 143-152.

Steinbrecher, N., Koerber, S., Frieser, D., \& Hiller W. (2011). The prevalence of medically unexplained symptoms in primary care. Psychosomatics, 52(3), 263-271.

Szemerszky, R., Köteles, F., Lihi, R., \& Bárdos, G. (2010). Polluted places or polluted minds? An experimental sham-exposure study on background psychological factors of symptom formation in 'Idiophatic Environmental Intolerance attributed to electromagnetic fields'. International Journal of Hygiene and Environmental Health, 213, 387-394. doi:10.1016/j.ijheh.2010.05.001

Tellegen, A., \& Atkinson, G. (1974). Openness to absorbing and self-altering experiences ("absorption"), a trait related to hypnotic susceptibility. Journal of Abnormal Psychology, 83, 268-277. doi:10.1037/h0036681

Ulrich-Lai, Y. M., Herman, J. P. (2009). Neural regulation of endocrine and autonomic stress responses. Nature Reviews Neuroscience, 10, 397-409. doi:10.1038/nrn2647

Van den Bergh, O., Bogaerts, K., \& Van Diest, I. (2015). Symptom perception, awareness and interpretation. In J. D. Wright (editor-in-chief), International Encyclopedia of the Social \& Behavioral Sciences, 2nd edition, Vol 23. (pp. 866-872). Oxford, England: Elsevier.

Van den Bergh, O., Kempynck, P. J., Van de Woestijne, K. P., Baeyens, F., \& Eelen, P. (1995). Respiratory learning and somatic complaints: A conditioning approach using $\mathrm{CO}_{2-}$ enriched air inhalation. Behaviour, Research and Therapy, 33, 517-527.

Van den Bergh, O., Stegen, K., \& Van de Woestijne, K. P. (1997). Learning to have psychosomatic complaints: Conditioning of respiratory behavior and somatic complaints in psychosomatic patients. Psychosomatic Medicine, 59, 13-23. 
Van den Bergh, O., Stegen, K., \& Van de Woestijne, K. P. (1998). Memory based symptom reporting in a respiratory learning paradigm. Health Psychology, 17, 241-248.

Van den Bergh, O., Stegen, K., Van Diest, I., Raes, C., Stulens, P., Eelen, P., ... et al., (1999). Acquisition and extinction of somatic complaints in response to odors : A paradigm relevant to investigate Multiple Chemical Sensitivity. Occupational and Environmental Medicine, 56, 295-301.

Van den Bergh, O., Winters, W., Devriese, S., \& Van Diest, I. (2002). Learning subjective health complaints. Scandinavian Journal of Psychology, 43, 147-152. doi:10.1111/1467-9450.00280

Van den Bergh, O., Winters, W., Devriese, S., Van Diest, I., Vos, G., \& De Peuter, S. (2004). Accuracy of respiratory symptom perception in persons with high and low negative affectivity: Psychology and Health. Psychology and Health, 19, 213-222. doi:10.1080/08870440410001675627

Van den Bergh, O., Witthöft, M., Petersen, S., \& Brown, R.W. (in press). Symptoms and the body: Taking the inferential leap. Neuroscience \& Biobehavioral Reviews

Van Diest, I., De Peuter, S., Piedfort, K., Bresseleers, J., Devriese, S., Van de Woestijne, K. P., ... et al., (2006). Acquired lightheadedness in response to odors using hyperventilation as US. Psychosomatic Medicine, 68, 340-347. doi:10.1097/01.psy.0000204782.49159.79.

Van Diest, I., Winters, W., Devriese, S., Vercamst, E., Han, J. N., Van de Woestijne, K. P., ... et al., (2001). Hyperventilation beyond fight/flight: Respiratory responses during emotional imagery. Psychophysiology, 38, 961-968.

Van Dongen, D., Smid, T., \& Timmermans, D. R. M. (2011). Perception of health risks of electromagnetic fields by MRI radiographers and airport security officers compared to 
the general Dutch working population: A cross sectional analysis. Environmental Health, 10, 95. doi:10.1186/1476-069X-10-95

Van Oudenhove, L., \& Aziz, Q. (2013). The role of psychosocial factors and psychiatric disorders in functional dyspepsia. Nature Reviews Gastroenterology and Hepatology, 10, 158-167. doi:10.1038/nrgastro.2013.10

Walentynowicz, M., Bogaerts, K., Van Diest, I., Raes, F., \& Van den Bergh, O. (2015). Was it so bad? The role of retrospective memory in symptom reporting. Health Psychology, 34, 1166-1174. doi:10.1037/hea0000222

Walentynowicz, M., Raes, F., Van Diest, I., \& Van den Bergh, O. (2016). The specificity of health-related autobiographical memories in patients with Somatic Symptom Disorder. Psychosomatic Medicine. DOI: 10.1097/PSY.0000000000000357

Wessely, S., Nimnuan, C., \& Sharpe, M. (1999). Functional somatic syndromes: One or many? Lancet, 354, 936-939. doi:10.1016/S0140-6736(98)08320-2

Winters, W., Devriese, S., Van Diest, I., Nemery, B., Veulemans, H., Eelen, P., ... et al., (2003). Media warnings about environmental pollution facilitate the acquisition of symptoms in response to chemical substances. Psychosomatic Medicine, 65, 332-338. doi: 10.1097/01.PSY.0000041468.75064

Witthöft, M., Gerlach, A. L., \& Bailer, J. (2006). Selective attention, memory bias, and symptom perception in idiopathic environmental intolerance and somatoform disorders. Journal of Abnormal Psychology, 115, 397-407. doi:10.1037/0021843X.115.3.397

Witthöft, M., Rist, F., \& Bailer, J. (2008). Evidence for a specific link between the personality trait of absorption and idiopathic environmental intolerance. Journal of Toxicology and Environmental Health part A, 71, 795-802. doi:10.1080/15287390801985687 
Witthöft, M., Rist, F., \& Bailer, J. (2009). Abnormalities in cognitive-emotional information processing in idiopathic environmental intolerance and somatoform disorders. Journal of Behavior Therapy and Experimental Psychiatry, 40, 70-84.

doi:10.1016/j.jbtep.2008.04.002

Witthöft, M., \& Rubin, G. J. (2013). Are media warnings about the adverse health effects of modern life self-fulfilling? An experimental study on idiopathic environmental intolerance attributed to electromagnetic fields (IEI-EMF). Journal of Psychosomatic Research, 74, 206-212. doi:10.1016/j.jpsychores.2012.12.002

Yiend, J. (2010). The effects of emotion on attention: A review of attentional processing of emotional information. Cognition and Emotion, 24, 3-47.

doi:10.1080/02699930903205698 
Stage 1: Symptom generation (according to the perception-as-inference approach)
Stage 2: Pairing of symptoms with environmental stimuli

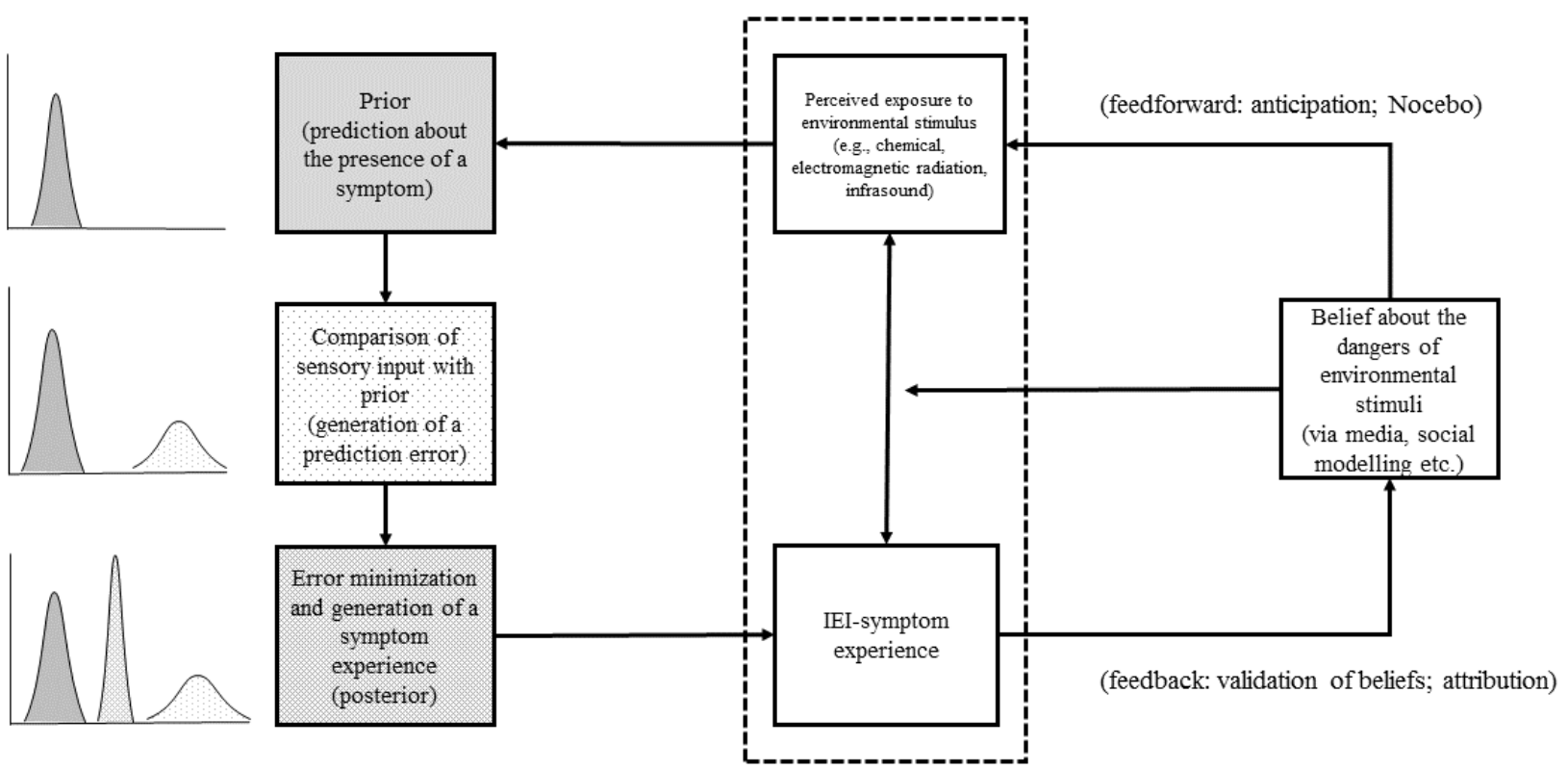

Figure 1: A simplified illustration of a perception-as-inference approach to IEI. Symptoms of IEI are hypothesized to result from somatic symptom experiences (stage 1) that become associated with environmental stimuli (stage 2). Once symptom-stimuli associations have been formed (e.g., via classical conditioning, social modelling), the perception of environmental stimuli is able to foster the formation of strong and precise priors that are able to determine conscious symptom perceptions in the posterior model. IEI-symptom experiences reinforce IEI related beliefs in memory (feedback route) and shape the priors of the symptom-perception model for upcoming symptom perception episodes (feedforward route). 
Table 1. Overview of core findings in laboratory studies on symptom learning in response to chemicals (left column) and correspondence with core features of clinical MCS (right column).

\section{Finding in the laboratory}

1. After a few symptom episodes induced by hyper- or hypocapnia associated with a harmless odor, the odor alone elicits elevated levels of somatic symptoms (Van den Bergh, Kempynck, Van de Woestijne, Baeyens, \& Eelen 1995; Van den Bergh et al., 1997; Van Diest, De Peuter, Piedfort, Bresseleers, Devriese, Van de Woestijne et al., 2006).

2. In-depth analysis focussing on lightheadedness caused by hypocapnia shows that the symptom is initially strongly related to reduced cerebral blood flow, but after a few episodes is uncoupled from this physiological source and elicited by a harmless odor cue alone (Van Diest et al., 2006; Bresseleers, Van Diest, De Peuter, Verhamme, \& Van den Bergh, 2010).

3. Learned symptoms specifically reflect the symptoms of the initially induced symptom episodes, and the emergence of learned symptoms in response to harmless cues is based on automatic activation of memories of the initial symptom episodes (Van den Bergh et al., 1997; Van den Bergh, Stegen, \& Van de Woestijne, 1998). However, with strong symptom challenges (e.g. 20\% $\mathrm{CO}_{2}$-enriched air), symptom reporting spreads to a wider range of symptoms than initially elicited (Meulders, Fannes, Van Diest, De Peuter, Vansteenwegen, \& Van den Bergh, 2010).
This finding represents the core feature of MCS: patients report symptoms in response to perceived but harmless chemicals as a result of expectancy learning. A toxic exposure and/or stress-related symptoms may possibly initiate this learning process.

Lightheadedness is one of the primary central nervous system complaints of MCS patients, but a physiological source can typically not be objectified in clinical investigations.

Phenomenally, symptom episodes automatically pop up after confrontation with chemical cues without preceding extensive conscious elaboration. It is likely that the emotional impact of the first symptom episodes moderates the extensiveness of the learned symptom profile. 
4. The causal belief about the odors inducing the symptoms is critical. When this belief is at odds with objective co-occurrences of odors and symptoms, symptom reporting reflects the erroneous beliefs rather than the objective co-occurrences (Devriese, Winters, Van Diest, De Peuter, Vos, Van de Woestijne, et al., 2004; Winters, Van Diest, \& Van den Bergh, 2004).

5. A priori beliefs, which may result from simply reading about the detrimental health effects of chemical pollution, additionally facilitate symptom learning (Winters et al., 2003).

6. Symptom learning is facilitated by negative valence of the odors: it occurs in response to foul smelling odors and not to pleasant ones, but when pleasant odors are given a negative meaning (e.g. framing perfumes as chemical pollution of our environment), symptom learning also occurs (Van den Bergh et al., 1997, 1999; Winters et al., 2003).

7. Symptom learning is more likely in persons with high neuroticism or trait negative affectivity, and in psychosomatic patients (Van den Bergh et al., 1995, 1997).

8. Learned symptoms generalize to newly presented odors following an unpleasantness gradient (Devriese et al., 2000).

9. Merely evoking an image of being in a particular room or situation that was previously associated with a symptom episode, elicits symptoms but only when the imagined situation was unpleasant or stressful (Stegen, De Bruyne, Rasschaert, Van de Woestijne, \& Van den Bergh et al., 1999).

10. Learned symptoms are persistent: no difference was found between the level of symptoms tested immediately after learning or after one week (Devriese et al., 2000).
In well-controlled blinded studies with MCS patients, symptoms elicited by chemical exposures are critically depending on knowledge that an exposure has been presented. Without such knowledge, no elevated symptoms emerge (see main text). This suggest a critical role of beliefs and expectations.

Clinically evidence suggest that a strong belief system about the role of environmental pollution, often shared with and fostered by patient organisations, contributes to the problem.

Case descriptions show symptoms occurring to a wide range of both unpleasant and pleasant smelling cues. Most patients have extremely negative belief systems about the impact of chemicals on health.

MCS is more likely in persons with high levels neuroticism. MCS patients also show elevated psychiatric co-morbidity (somatization, overlap with other functional syndromes).

MCS patients typically show a gradual increase over time of the number and type of odorous chemicals that trigger the symptoms.

Case descriptions suggest that patients may report symptoms when entering rooms that supposedly contain chemicals. This is consistent with the critical role of expectations. However, images of rooms or situations as triggers for symptoms have not been investigated in clinical studies.

Symptoms of clinical cases are known to be persistent: after one year, the symptoms are still present in $92 \%$ of the cases. 
11. Learned symptoms can be extinguished or "unlearned". A series of exposures to the odor alone eliminated learned symptoms, showing that corrective experiences are able to change the beliefs. However, this process is hampered by highly intense initial learning episodes (e.g. with $20 \% \mathrm{CO}_{2}$ - enriched air, Meulders et al., 2010).

12. When presenting odor stimuli together with information framing the odor in a negative way to persons scoring high on trait negative affectivity and/or prone to high symptom reporting, the correspondence between $\mathrm{CO}_{2}$-induced physiological changes and self-reported symptoms drops substantially (Van den Bergh et al., 2004; Bogaerts et al., 2005, 2008).
Favorable outcomes of cognitive-behavioral treatments are reported, including exposure therapy and interventions trying to alter beliefs and avoidance behavior. However, no RCT's of psychological treatments exist thus far.

Even when relevant physiological changes are observed in vulnerable persons or patients, the self-reported symptoms do not necessarily reflect or closely correspond with these physiological changes. The relationship between reported symptoms and observed physiological changes should not be readily assumed, but tested on a within-person basis. 


\section{Supplemental Online Material (SOM-R)}

Table S2 Description and main findings of brain imaging studies testing the effect of real and sham environmental stimuli on neuronal processes and behavioural measures (of affective evaluation and symptom experiences) in patients suffering from environmental intolerances (IEI) compared to healthy controls

\begin{tabular}{|c|c|c|c|c|}
\hline Reference & Manipulation & Behavioral measures & Result & Methods and brain-related measures \\
\hline $\begin{array}{l}\text { Landgrebe } \\
\text { et al. (2008) }\end{array}$ & sham exposure to mobile phone & $\begin{array}{l}\text { unpleasantness } \\
\text { anticipation }\end{array}$ & $\begin{array}{l}\text { IEI-EMF > healthy } \\
\text { controls }\end{array}$ & $\begin{array}{l}\text { fMRI } \\
\text { aINS \& ACC } \\
\text { fusiform gyrus } \\
\end{array}$ \\
\hline $\begin{array}{l}\text { Hillert et al. } \\
\text { (2007) }\end{array}$ & odorants vs. odorless air & $\begin{array}{l}\text { irritability, } \\
\text { pleasantness, intensity }\end{array}$ & $\begin{array}{l}\text { MCS > healthy } \\
\text { controls }\end{array}$ & $\begin{array}{l}\text { PET } \\
\text { aINS \& cuneus/precuneus }\end{array}$ \\
\hline $\begin{array}{l}\text { Orriols et al. } \\
(2009)\end{array}$ & $\begin{array}{l}\text { plastic-based paint for } 9,15,17, \\
23 \text { and } 35 \text { min } \\
\text { perfume, petrol and } \\
\text { glutaraldehyde for } 15,20 \text { and } 3 \\
\text { min }\end{array}$ & $\begin{array}{l}\text { poorer quality of life \& } \\
\text { neurocognitive } \\
\text { function at baseline, } \\
\text { and neurocognitive } \\
\text { worsening after } \\
\text { chemical exposure }\end{array}$ & $\begin{array}{l}\text { MCS > healthy } \\
\text { controls }\end{array}$ & $\begin{array}{l}\text { SPECT } \\
\text { basal hypoperfusion in small cortical areas of } \\
\text { the right parietal and both temporal and } \\
\text { fronto-orbital lobes; } \\
\text { after chemical challenge hypoperfusion in } \\
\text { olfactory, bl hippocampus, } \mathrm{r} \\
\text { parahippocampus, } \mathrm{r} \text { amygdala, } \mathrm{r} \text { thalamus, bl } \\
\text { Rolandic, rtemporal cortex regions } \\
\end{array}$ \\
\hline $\begin{array}{l}\text { Hillert et al. } \\
\text { (2013) }\end{array}$ & no stimulation & $\begin{array}{l}\text { higher trait harm } \\
\text { avoidance, } \\
\text { different emotional } \\
\text { modulation of acoustic } \\
\text { startle }\end{array}$ & $\begin{array}{l}\text { MCS > healthy } \\
\text { controls }\end{array}$ & $\begin{array}{l}\text { PET } \\
\text { lower 5-HT1 A receptor binding potential in } \\
\text { amygdala, ACC, insula }\end{array}$ \\
\hline
\end{tabular}




\begin{tabular}{|c|c|c|c|c|}
\hline $\begin{array}{l}\text { Chiaravalloti } \\
\text { et al. (2015) }\end{array}$ & $\begin{array}{l}\text { neutral olfactory (saline; NS) } \\
\text { and pure olfactory stimulation } \\
\text { (vanillin; OS) }\end{array}$ & & $\mathrm{OS}>\mathrm{NS}$ & $\begin{array}{l}\text { PET/CT } \\
\text { healthy controls: increased glucose } \\
\text { consumption in BA } 18 \text { and } 19 \text {, reduced } \\
\text { consumption in BA } 10,11,32 \text { and } 47 \\
\text { MCS: increase in BA 20, 23, } 18 \text { and } 37, \\
\text { decrease in BA } 8,9 \text { and } 10\end{array}$ \\
\hline $\begin{array}{l}\text { Azuma et al. } \\
(2015)\end{array}$ & $\begin{array}{l}\text { card-type olfactory identification } \\
\text { test kit (mandarin orange, } \\
\text { Japanese cypress, menthol, and } \\
\text { perfume) }\end{array}$ & $\begin{array}{l}\text { subjective assessment } \\
\text { of the physical \& } \\
\text { psychological status \& } \\
\text { of the perception of } \\
\text { irritating \& hedonic } \\
\text { odors }\end{array}$ & $\begin{array}{l}\text { MCS > healthy } \\
\text { controls }\end{array}$ & $\begin{array}{l}\text { near-infrared spectroscopy (NIRS) } \\
\text { bilateral PFC, OFC } \\
\text { autonomic perception \& feelings identification } \\
\text { were poorer in patients with MCS }\end{array}$ \\
\hline $\begin{array}{l}\text { Azuma et al. } \\
(2013)\end{array}$ & $\begin{array}{l}\text { card-type olfactory identification } \\
\text { test kit (mandarin orange, } \\
\text { Japanese cypress, menthol, and } \\
\text { perfume) }\end{array}$ & $\begin{array}{l}\text { subjective assessment } \\
\text { of the physical \& } \\
\text { psychological status \& } \\
\text { of the perception of } \\
\text { irritating \& hedonic } \\
\text { odors }\end{array}$ & $\begin{array}{l}\text { MCS > healthy } \\
\text { controls }\end{array}$ & $\begin{array}{l}\text { near-infrared spectroscopy (NIRS) } \\
\text { bilateral PFC }\end{array}$ \\
\hline $\begin{array}{l}\text { Bornschein } \\
\text { et al. }(2002) \\
\text { paper no } \\
\text { accessible }\end{array}$ & no stimulation & & $\begin{array}{l}\text { MCS > healthy } \\
\text { controls }\end{array}$ & $\begin{array}{l}\text { PET } \\
\text { mild glucose hypometabolism in } 1 \text { out of } 12 \\
\text { patients } \\
\text { group comparison: no differences }\end{array}$ \\
\hline
\end{tabular}


IDIOPATHIC ENVIRONMENTAL INTOLERANCE 55

\begin{tabular}{|l|l|l|l|l|}
\hline $\begin{array}{l}\text { Heuser \& } \\
\text { Wu (2001) }\end{array}$ & no stimulation & $\begin{array}{l}7 \text { MCS patients (all } \\
\text { had been exposed to } \\
\text { solvents, pesticides, } \\
\text { etc. before) > healthy } \\
\text { controls }\end{array}$ & $\begin{array}{l}\text { Pypometabolism "many cortical areas" } \\
\text { Hypermetabolism in limbic system and } \\
\text { adjacent structures }\end{array}$ \\
\hline
\end{tabular}

Note. MCS = Multiple Chemical Sensitivity; IEI = Idiopathic Environmental Intolerance; IEI-EMF = Idiopathic Environmental Intolerance attributed to Electromagnetic Fields; NS = Neutral Stimulation; OS = Olfactory Stimulation; PET = Positron Emission Tomography; CT =

Computed Tomography; fMRI = Functional Magnetic Resonance Imaging; SPECT = Single Photon Emission Computerized Tomography; BA = Brodmann Area; aINS = anterior Insular; ACC = Anterior Cingulate Cortex; PFC = Prefrontal Cortex; OFC = Orbitofrontal Cortex; 